\title{
Soil Health
}

\section{Daoren Tuya Wang Qi Mei Ruhong}

Chen Yanxi Microecology Team, China Agricultural University

\begin{tabular}{|c|c|}
\hline ARTICLE INFO & ABSTRACT \\
\hline Article history & \multirow{7}{*}{$\begin{array}{l}\text { Soil deterioration is caused by biological, physical and chemical factors } \\
\text { and can not be attributed to chemical fertilizers. Based on the concept of } \\
\text { soil health, we use biological, physical and chemical measures to regu- } \\
\text { late ecological balance and achieve the remediation goal. Soil is a small } \\
\text { universe. The biological, physical and chemical systems engineering in } \\
\text { the five levels of ecology should be used to control soil, restrain deteri- } \\
\text { oration, repair balance and realize soil rehabilitation. This paper focuses } \\
\text { on the correlation between soil health and inorganic fertilizer factors, and } \\
\text { from microecology, regulates the dynamic balance of soil microecology } \\
\text { with probiotics to achieve the goal of healthy soil fertility. }\end{array}$} \\
\hline Received: 22 April 2021 & \\
\hline Accepted: 24 May 2021 & \\
\hline Published Online: 31 May 2021 & \\
\hline Keywords: & \\
\hline & \\
\hline remediation & \\
\hline microecology & \\
\hline
\end{tabular}

\section{Soil Health}

Xi Jinping proposed the concept of "Big Health." The "Healthy China 2030" plan focuses on the people, building a healthy environment, building healthy soil and developing healthy industries. Xi Jinping proposed the "Community of Common Health for Mankind" to vigorously promote the development of soil health industry.

Soil is an important part of the earth's biosphere and the foundation of natural and artificial ecosystems. Soil is alive, according to the "Qian Xuesen Great Health" concept, soil is the basis of human life activities.

Ten thousand years ago, "in the natural ecosystem", the soil maintained its own ecological balance. Ten thousand years later, it comes into the agroecosystem. The agroecosystems can be divided into primitive agroecosystems $(10,000$ 3,000 years). People used stone and wood tools, with manpower, and the cultivation method was slash-and-burn, which was an extensive management. The soil basically maintains the state of natural ecosystem with little change. From the primitive agro-ecological system to the traditional agro-ecological system (from 3000 to 300 years), People used iron tools, powered by animal power, and started continuous cropping, and the operating condition was intensive labor management. Soil deterioration sometimes occurred but was not very serious. Only in the recent 300 years, in the modern agricultural ecosystem, people used machinery, powered by steam engine (1760), electricity (1840), and began to crop rotation. The crop varieties became single, commodity production appeared, and the operating condition was capital intensive management. In particular, in 1828 German chemist Wohler (F. W \& ounl. hlel, 1800-1882) synthesized urea by artificial method for the first time in the world. Although fertilizers accounted for about $40 \%-60 \%$ of the total crop yield increase, the soil deteriorated due to over application and improper application. With the addition of industrial pollution, agricultural waste, sewage irrigation, atmospheric pollutant settlement, heavy metal-containing mineral chemical fertilizers, chemical pesticides and so on, the soil gradually deteriorated, and some soil seriously deteriorated, especially by heavy metal pollution.

Soil deterioration causes: 1 . Crop reduction and quality decline; 2. Destroying dynamic balance of organisms and microorganisms in the soil and decreasing soil vitality; 3 . Affecting human and animal health and increasing disease death rate; 4 . Change of physical condition of soil and soil binding; 5. Decline of many animals, plants and microorganisms and serious imbalance.

Soil health is so seriously polluted that it is imperative to maintain soil health.

\section{Soil is a Small Universe}

\section{1 "Grandpa will be greater in the twenty-first century"}

Qian Xuesen (1911-2009) put forward "Human Life 
Science" in the 1960s. The seventh scientific and technological revolution represented by human life science is not a simple the meaning literally, but represents the progress of future science and technology. All progress in biological, physical and chemical sciences will be reflected in the human life sciences. Therefore, Qian Xuesen's human life science is the perfect integration of most advanced science in the west and the traditional Chinese science, which is the only independent and innovative high-tech science with Chinese characteristics.

In the last century, when Qian Xuesen won the Medal of Merit of "Two Bombs and One Star," his grandson said, "Grandpa is great." Qian said "Grandpa will be greater in the twenty-first century," he told people: "Human science may lead to a scientific and technological revolution in the twenty-first century, perhaps a scientific revolution greater than quantum mechanics and relativity theory in the early twentieth century!"

\subsection{Soil is a small universe}

Qian Xuesen thought that the human body is a small universe, because all the functions of the universe have a reaction on the human body, and the human body also reflects the existence and function of the universe at all levels.

We know that our bodies are made of atoms of the quantity of 1028. We have somatic cells of the quantity of 1013 and bacteria in human body of the quantity of 1014 . These 1028 magnitude of atoms form about 60 different elements, but the elements constituting human body are only 11 . Atoms form molecules by covalent bonds. The molecules come together to form aggregates, then form small organelles, cells, tissues, organs, and finally a whole human body.

We know that all substance are made up of atoms, that is, biological, physical, chemical substance are made up of atoms. Atoms form molecules, molecules form aggregates, and aggregates as mentioned previously eventually form the whole body of a human. The aggregates also form grains and animals. Aggregates also form physical substances, such as steel and chemicals, such as oil. Thus, all substances are made up of atoms, which are made up of basic particles. So everything goes back to the basic particle level, and they all have commonalities. Inorganic fertilizers, organic fertilizers, microbial fertilizers are also made up of atoms, the existence of commonalities is inevitable.

\subsection{Five levels of ecology, three levels of regulation and one goal}

The whole universe is divided into space ecology, mac- roecology, microecology, molecular ecology and elementary particle ecology. The mechanism of maintaining soil health is cognized from these five levels. And the goal of "soil health" will be realized through "biological, physical and chemical" regulation. We study the "five levels, three regulations, one goal" model of soil health to achieve the "community of shared future for mankind," and "community of human health."

\section{Maintenance of Soil Ecological Balance}

Zhu Fengmei (1895-1970), a senior in plant pathology, reported in 1962: "You can study lunar soil very clearly, but if I take a handful of campus soil, you never know it. Because it is alive and evolving, it is dynamic, and you can only recognize this dynamic balance. You can only learn it, study it, adapt to it, and maintain this dynamic balance!"

Inorganic chemical fertilizers are confined to inorganic nitrogen $(\mathrm{N})$, phosphorus $(\mathrm{P})$, potassium $(\mathrm{K})$ and these are collectively called chemical fertilizers. It is related to soil deterioration, and it is necessary to maintain the dynamic balance of three elements in soil remediation. The use of chemical fertilizers is regulated to the optimal dynamic balance threshold of economic, ecological and social benefits, and the biological, physical and chemical regulation measures are used to maintain soil health continuously.

\subsection{Soil deterioration can not all be attributed to chemical fertilizers}

We recognize soil as a small universe.

Chemical fertilizers account for $40 \%-60 \%$ of the contribution rate of grain increase in China, and the cultivated land accounts for $7 \%$ of the world, but it feeds $20 \%$ of the world population.

There are many factors causing soil deterioration, including biological, physical and chemical factors Chemical fertilizers cause residue and pollution due to unscientific use. In different areas, due to different soil and different soil management, there are many other factors causing soil deterioration, not only the use of chemical fertilizers.

\subsection{Dialectical understanding of "not applying fertilizers"}

Currently there are many unhealthy issues, such as climate warming, environmental deterioration, especially soil deterioration, soil urgent to repair, and so on. The State implements the "Healthy China 2030" regulation outline and implements the" Big Health Concept ". Soil health is first among them. The organic offered not to 
apply fertilizers. Many businesses use "no chemical fertilizer" as their broadcast to promote their so-called "organic food" or "green food".

Subjectively, we should look at the deterioration of soil from the dialectical point of view, objectively follow the principle of nature, maintaining the dynamic ecological balance of soil, and actively solve the soil pollution, soil poisoning, soil slates, soil disease aggravation and other numerous negative issues. We should "advocate dialectics, follow nature" and maintain the dynamic balance of soil. We can apply chemical fertilizers, but build healthy, sustainable healthy soil, as long as there is no residue and no pollution.

We should take soil deterioration as the result of the historical development process and our scientific development process. We should acknowledge that chemical fertilizers have contributed in the historical development process. We should not negate them all. Meanwhile we need to value its negative issues. Things have duality, we should "increase benefits and reduce harm."

Farmers didn't accept it when they began to promote "fat field powder "(ammonia sulfate) more than 60 years ago, but it could increase production and ensure a good harvest. People accepted it and became increasingly dependent on it. The application rate of chemical fertilizers rose sharply, and the excessive application and the uncontrolled use of chemical fertilizers paid attention to the "benefits increase" and neglected the "harm reduction", resulting in various ills of soil health, and the "soil remediation" had to put on the schedule and became more and more urgent.

Today, instead of negating chemical fertilizers totally, we should reduce the harm of chemical fertilizers to the economic, ecological and social three-benefit threshold. We should use chemical fertilizers according to soil and crop environment, with timely and appropriate methods. If the use of fertilizer can be achieved without residue and pollution, then everyone will be happy. We have used yield-increasing beneficial bacteria to degrade nitrate content in crops and actively eliminate residues of chemical fertilizers. This is the active solution on the basis of active prevention and control and has index significance. The human, material and financial resources of chemical fertilizer research and development are used to study the "man-made disaster of chemical fertilizer", so as to make it "increase benefits and reduce harm," which will surely get higher and better results than just prevention.

\subsection{Regulation of soil health}

Soil health regulation is a systematic project, soil remediation is a link of soil health regulation. There are five links of soil health: 1) soil health monitoring; 2) prevention of soil deterioration; 3 ) diagnosis of soil deterioration; 4) soil remediation; 5) soil rehabilitation.

We want to look at soil "medicine" with the concept of health medicine. The diagnosis of soil deterioration is like that we go to the hospital to see a doctor, in the soil "medicine", the doctor carries out indoor and outdoor survey, diagnoses the soil "disease." "Soil remediation" is like the treatment after diagnosis.

Therefore, before "diagnosis", there are two links, namely, "soil health monitoring" and "prevention of soil deterioration."

"Soil health monitoring", like human, is monitored from fetus, birth, growth, life and death. As for the soil, we should monitor it at all times. Especially when we enter the "cloud" era, we have "Beidou" and "Huawei." We can clearly monitor the changes of the soil at all times, and the dynamic balance between the "benefit" and "harm." Therefore, there is the second link, "prevention of soil deterioration." When something is wrong in the process of monitoring the dynamic balance of soil, we adopt biological, physical and chemical techniques to keep the "benefit" and "harm" of soil health within the three-effect threshold of economy, ecology and society. Only if the dynamic balance of soil is seriously out of balance, we can enter the "diagnosis" and "remediation." Soil health management and control is after "remediation," and there is also the fifth link "soil rehabilitation." We should not think the job is done after the "remediation", but should be proactively into the fifth link "soil rehabilitation." In the "rehabilitation" phase, it is necessary to consolidate the "remediation" effect and control other soil deterioration factors. To realize the dynamic balance of soil health in "health $\leftrightarrow$ sub-health $\leftrightarrow$ deterioration $\leftrightarrow$ remediation $\leftrightarrow$ sub-health $\leftrightarrow$ health," and to promote the dynamic balance to benefit three-benefit threshold.

We need to maintain the dynamic balance of soil health from "advocating dialectics and following nature."

Monitor $\leftrightarrow$ Prevention $\leftrightarrow$ Deterioration $\leftrightarrow$ Diagnosis $\leftrightarrow$ Remediation $\leftrightarrow$ Rehabilitation.

\section{Theory and Practice of Microecological Soil Remediation}

Professor Chen Yanxi (1924-2010) participated in the revolution in 1932 and was the third generation master of plant pathology in China. In his long-term revolutionary experience, he was familiar with dialectics and followed the principle of nature: attaching importance to relating the theory with the practice, and putting practice the first place. In 1976, he led a team to create "microecology," 
which is defined as: the biological individual is a complex of cell tissue and microorganisms, and it is the branch of life science studying the composition, function and substitution of these microorganisms, the relationship among the microorganisms, and the relationship between microorganism and microenvironment of organism.

We think the soil is a small universe, the five ecological levels respond in the scope of soil, but the microecological level is most intuitive, visible for us. We emphasize the use of biological, physical and chemical soil remediation techniques to control the deterioration of soil.

Soil deterioration factors are complex, and soil remediation measures are more complex. In this paper, the microbial factors in soil are discussed.

As mentioned previously, soil is lively and a small universe, mainly because of microbes in the soil.

More than 3 billion years ago. We are living in a microbial world. Microorganisms are classified as bacteria, fungi, algae, commonly known as parasites of the protozoa and worms, another category, namely viruses. A virus is a simple organism that can only be replicated in living cells. It is not strictly considered as a living organism, but it is also attributed to microorganisms.

Microbes evolved from aquatic ones to terrestrial ones, and from simple to complex. The terrestrial microbes live early on in the crust. So far in today's soil, there are very many microorganisms living in the $20 \mathrm{~cm}$ tillage layer. The microbial communities, species and numbers in this tillage layer change from time to time. The microbial population and its quantity in the soil and its biological yield are changing under various tillage conditions, different crop species and different growth stages. In the last century, our team spent 10 years in Langfang cotton wilt disease nursery, monitoring systematically cotton wilt bacteria. It also took ten years to make a systematic investigation and study on the condition dynamics of wheat all-etching disease in Fengning Dam. Professor Wang Qi has conducted a study since 2006 . He divided two mu (approximate 66.5 square meters) of field in Shangzhuang experimental area of our university into six plots, one of which uses compound chemical fertilizer and the other five use organic fertilizer to different gradients. The experiments have been carried out for 14 years, and the soil microflora has been analyzed year by year, as well as the observation and study of the biological yield and characters of wheat-maize crops.

Soil deterioration is caused by biological, physical and chemical factors. We use micro-organisms to regulate the biological, physical and chemical factors of soil deterioration based on microecology and its business theory and practice. Microecological regulation technology is used to repair soil, reach the economic, ecological and social benefit threshold, and build healthy soil.

\section{Case of Building Healthy Soils -- Preven- tion and Treatment of Soil-borne Diseases}

\subsection{Self-healing power of healthy soil}

\section{Wheat take-all}

(1) Wheat take-all is widely distributed all over the world. It was first recorded in the UK in 1884, and was first discovered in Zhejiang Province in China in 1931. In the early 1970s, wheat take-all occurred seriously in Huangxian County, Yantai, Shandong Province, and was expanded to 19 provinces. It is a devastating disease and can go out of production.

(2) Wheat Take -all is a continuous cropping disease, which is aggravated year by year. When the incidence rate and severity of the disease reach the peak, the disease index continues to decrease year by year, and the crop yield increases due to the reduction of the disease. This phenomenon is called a "take- all decline (TAD)." The peak period of disease usually lasts 1-3 years. After the peak period, the disease declined at different rates due to different soil health. The mechanism of TAD is mainly associated with the beneficial microbes in the soil.

(3) In the last century, we spent ten years on Fengning Dam to systematically observe the whole process of wheat take-all disease in one mu of wheat field: onset - severe disease - decline - mild disease - basically no disease. The generation of orange resistance soil is related to the population and quantity of beneficial microorganism in soil. Therefore, in laiwu, Shandong province, we increased the application of organic fertilizer, nitrogen fertilizer, and use beneficial bacteria such as Pseudomonas fluoresceae, Bacillus, and other microbial fertilizer, and achieved good results.

The application of nitrogen fertilizer and probiotics accelerated the increase of resistance to wheat take-all disease, and eventually the disease declined and gradually eliminated. Later, in huangxian county, there was no single sample of wheat take-all disease found. Soil is a living organism and has the ability to heal itself.

\subsection{Comprehensive treatment of microecological regulation}

\section{Fusarium wilt of cotton}

(1) Fusarium Wilt of Cotton can occur from seedling stage to adult stage, and reach the peak before and after budding. Fusarium oxysporum can survive for 6-7 years in soil and chlamydospores can survive for up to 15 years. 
The pathogen mainly intrudes from the epidermal cells or wounds of cotton plants. The pathogen intrudes through the cortex and enters the catheter, and propagates and expands in the catheter, distributing to the whole plant.

(2) In the 1970s and 1980s, our team established a plant nursery for studying Fusarium wilt of cotton in Langfang, Hebei Province, and conducted systematic observation and research on Fusarium wilt for ten years.

Fusarium oxysporum occurred in the soil, through the root surface, into cotton, then into the vascular, extending the whole plant. In this process, Fusarium oxysporum broke through the layers of microbial protection in the natural ecosystem of cotton, so as to seriously develop in the bud stage of cotton.

The prevention and treatment of Fusarium wilt of cotton should adopt comprehensive management strategies of protecting disease-free areas (fields), eliminating sporadic areas (fields), controlling light areas (fields) and reforming seriously ill areas (fields).

Microecological preparations such as Bacillus and Trichoderma can be used for microecological regulation of wilt disease. For example, when sowing, biological control preparations were used in combination with seed fertilizer, seed disinfectant and seed granulation technology; i.e., microecological preparations were used near the seeds. a. Isolation agent was added. b. Middle layer was fertilizer, and isolation agent was added. c. The outer layer was seed chemical disinfectant. $d$. The isolation layer can be made of methyl cellulose and other film forming agents.

Microbial bacteria were used as base fertilizer to control the propagation of Fusarium wilt bacteria in soil and reduce infection potential.

Microecological bacteria formed bacteriostatic soil in cotton rhizosphere, reducing the infection potential and infection rate of Fusarium wilt bacteria.

During the growing period of cotton, microecological preparation was sprayed especially at the lower petiole of cotton buds, to slow the spreading of wilting bacteria in vascular bundles. Enhanced microecological preparation used at the lower petiole of the buds can retain the first and second leaves under the buds, and cotton can retain basic biological production.

In order to control Fusarium wilt of cotton more effectively, microecological preparations can be combined with other disease control measures.

\section{Dynamic Balance of Soil Microecology is the Foundation of Soil Remediation}

\section{Dynamic balance of soil microflora}

As for that the treatment of wheat take-all disease, Fu- sarium wilt of cotton followed the principle of "dialectics and nature" and used the concept of microecological regulation to view the dynamic balance of microbial "increase benefits and reduce harm" in soil remediation.

Microecological fertilizer is the basic measure to control soil deterioration. In "bacteria fertilizer" concept, "bacteria" is referred to microbial, and "fertilizer" can be organic fertilizer, or inorganic fertilizer. There are traditional bacteria - rhizobia, nitrogen-fixing bacteria, phosphorus and potassium - releasing bacteria, pro-growth bacteria, mycorrhizal bacteria, photosynthetic bacteria, organic rotting bacteria. While this paper mainly focuses on Bacillus, centering on the soil remediation of organic fertilizer.

Since 1976, the microecology team of China Agricultural University has pioneered the application of Bacillus as bacterial fertilizer and bacterial medicine.

In 1979, the yield-increasing beneficial bacteria with Bacillus as the main body was introduced.

Our team has been insisting for decades that each functional bacterium is fermented in a single way, and then "suit the remedy to the case," forming a variety of compound bacterial agents aimed at a variety of deteriorated soil to different extent.

As mentioned earlier, Professor Wang Qi started study on one mu of cotton field in 2006, divided into six districts, one with compound fertilizer and the other five with organic fertilizer according to different gradients. It has been fourteen years, and the changes of soil microflora have been observed and studied year by year.

If the soil deteriorates, then the soil is repaired. A comprehensive scientific judgment must be made according to the concept of system engineering, so that the disease can be repaired.

Case: Obstacles to continuous cropping

Repeated stubble disease

Repeated stubble disease is the cancer in soil-borne disease

The planting of the same crop in the same plot for several consecutive seasons or for many years is called "repeated stubble" in cultivation.

Repeated stubble disease is an iconic disease of soil deterioration. Soil compaction, blind fertilization, high soil salinity and other factors are the reasons of soil erosion. While the reducing of soil beneficial microorganisms and microbial metabolites resulting in dynamic imbalance is the root cause of serious stubble disease.

In 2018, our team carried anti-stubble preparations in the Third China Innovation Challenge (Lanzhou), won the winning team (first prize), helping to solve the planting technical problems in summer on plateau. On September 
5 , at on-site observation and promotion conference of the effect of technology solving needs in China Innovation Challenge (Lanzhou lily), lily increased production by more than 500 yuan per mu in the test area, with an increase rate of up to $20 \%$. A perfect answer was submitted by China Agricultural University for anti-stubble microecological preparations. For many years, sunflower and other crops have been successfully controlled repeated stubble diseases.

Anti-stubble agent is the international leading innovation of China Agricultural University. Bacteria, such as Bacillus, Trichoderma, Actinomycetes, Scopulariomycetes, which were used to prevent and control repeated stubble diseases, were selected to prevent disease, promote growth and produce high yield. Specialized fermentation techniques were used for single-strain fermentation. According to the main factors of soil deterioration, special bacteriological agents were combined with other agricultural measures to prevent and control repeated stubble diseases.

In the anti-pandemic days, our team in Daxing Panggezhuang Beijing succeeded at the prevention of watermelon root knot nematode by nematode-prevent microecological preparation. According to the principle of plant microecology, the nematode-prevent microecological preparation was a compound microecological preparation developed by single strain fermentation and multi-strain compounding and other special fermentation technology and preparation processing technology. Probiotics multiplied rapidly and produced many metabolites when applied to soil. Dominant flora formed in the soil, forming a tight protective layer around plant roots, which in turn reduced the incidence of root knot nematodes.
In this case, it is clear that micro-organisms are used to regulate the dynamic balance of soil micro-ecology, increasing benefits and reducing harm, inhibiting soil deterioration and making the soil develop healthily. Of course, microbial regulation and control should be combined with biological, physical and chemical control measures to actively repair deterioration factors and maintain soil health.

\section{References}

[1] Chen Yanxi. Trans. Plant Root Disease Fungi. Agricultural Press. 1956.

[2] Mei Ruhong. Biological Control of Take-All Disease in Wheat [J]. Journal of Beijing Agricultural University 8 (2). 1982.

[3] Ecological Research of Soil-borne Plant Pathogens. 1983. Research Institute of Plant and Biological Control for Plant Diseases, Beijing Agricultural University.

[4] Mei Ruhong. Yield-increasing Bacteria. Agriculture Press. 1989.

[5] Ji Pingsheng. The Mechanism of the Yield-increasing Bacteria [J]. Chinese Journal of Microecology 3 (1): 92-95. 1991.

[6] Lu Suyun et al. Biological Control of Plant Diseases. Beijing Agricultural University Press. 1993.

[7] Mei Ruhong. Plant Microecology. Agricultural Press. 1998.

[8] Baker K. F., Cook R. J. Biological Control of Plant Pathogens. San Francisco Freeman. 1974.

[9] Georgeo N. Agrios. Disease Control by Immunizing, or Improving the Resistance of, the Host Plant Pathology (Fourth Edition) 192-195. Academic Press. 1997. 